\title{
Low Incidence of Childhood Celiac Disease in The Netherlands
}

\author{
E. K. GEORGE, M. L. MEARIN, E. A. van der VELDE, R. H. J. HOUWEN, J. BOUQUET, \\ C. F. M. GIJSBERS, AND J. P. VANDENBROUCKE
}

Departments of Pediatrics [E.K.G., M.L.M.], Medical Statistics [E.A.V.], and Epidemiology [J.P.V.], University Hospital Leiden; Wilhelmina Children's Hospital, Utrecht [R.H.J.H.]; Sophia Children's Hospital, Rotterdam [J.B.]; and Juliana Children's Hospital, The Hague [C.F.M.G.], The Netherlands \begin{abstract}
ABS
The incidence and prevalence of celiac disease vary interna-
tionally. We studied the incidence of identified cases of childhood celiac disease in six Dutch provinces that cover $47.9 \%$ of the surface area and $67.6 \%$ of the total population of The Netherlands. Children with celiac disease aged 0-14 y, diagnosed from January 1975 to January 1991, were traced by 1 ) contacting all pediatricians in this area, 2) examining the data of the Dutch National Medical Registration, and 3) investigating the membership records of the Dutch Celiac Disease Society. These data were cross-checked by the Dutch Network and National Database of Pathology. Of the $97.9 \%$ of pediatricians who answered our inquiry, $46.1 \%$ were treating celiac patients. A total of 342 celiac patients were identified. Informed consent that
\end{abstract}

The incidence of childhood celiac disease shows remarkable variations in different European countries, ranging from 1:300 live births in the western part of Ireland to 1:3500 in other countries $(1,2)$. Variations within the same country have also been reported $(3,4)$. Increases and decreases in the incidence of celiac disease have been described $(4,5)$. Breast-feeding, the age of gluten introduction, and the amount of gluten intake, as well as the use of different diagnostic criteria may play a role in the varying incidence of celiac disease (6). Recently, an increase in atypical clinical presentation of celiac disease, which may include recurrent abdominal pain, constipation, iron-resistent anemia, or short stature, has been described in children (7) and in adults $(8,9)$. Differences in diagnostic awareness may result in incomparable data on incidence and prevalence (10).

In The Netherlands, little is known about the incidence of childhood celiac disease. Based on the membership records of the Dutch Celiac Disease Society, a crude estimated prevalence of 12/100,000 inhabitants, both children and adults, was found in 1992 (11). This is remarkably low compared with neighbor-

Received December 6, 1993; accepted August 30, 1994

Correspondence: E. K. George, M.D., University Hospital Leiden, Department of Pediatrics, P.O. Box 9600, 2300 RC Leiden, The Netherlands.

Supported by the Dutch Society for Pediatric Gastroenterology and Nutrition. permitted examination of their medical files was given by $97.3 \%$ of the parents of the celiac children. The mean crude incidence rate of diagnosed childhood celiac disease, calculated per 1000 live births per year, was 0.18 . However, a significant increase in reported incidence was demonstrated from 0.10 in 1976 to 0.32 in 1990. The best estimate, for the years 1985-1990, is $0.22 / 1000$ live births, which is much lower than in most European countries. (Pediatr Res 37: 213-218, 1995)

Abbreviations
ESPGAN, European Society for Paediatric Gastroenterology
and Nutrition

ing countries. However, not all celiac patients are members of the Society. To investigate whether the prevalence and incidence of childhood celiac disease in The Netherlands are really that low, we started an extensive search, relying not only on the records of the Celiac Disease Society, but also on the files of pediatricians, the data of the Dutch National Medical Registration, and the Dutch Network and National Database of Pathology.

\section{METHODS}

Data collection. Six Dutch provinces (Zuid-Holland, NoordHolland, Gelderland, Limburg, Utrecht, and Groningen), covering $47.9 \%$ of the Dutch surface area and $67.6 \%$ of the total Dutch population, were studied (Fig. 1). This area comprises the four largest Dutch cities (Amsterdam, Rotterdam, The Hague, and Utrecht), all eight university hospitals in The Netherlands, and two agrarian districts and is representative of The Netherlands as a whole. Demographic and epidemiologic data of the general population were provided by the Dutch Central Bureau of Statistics (12). The emigration and immigration rates in the 18 - to 40 -y-old patients remained stable: $2.7 \%$ in 1980 and $2.8 \%$ in 1989 for both. In the area, 1917232 children were born between 1975 and 1991. The distribution of these births over the provinces also remained stable. Ninety- 


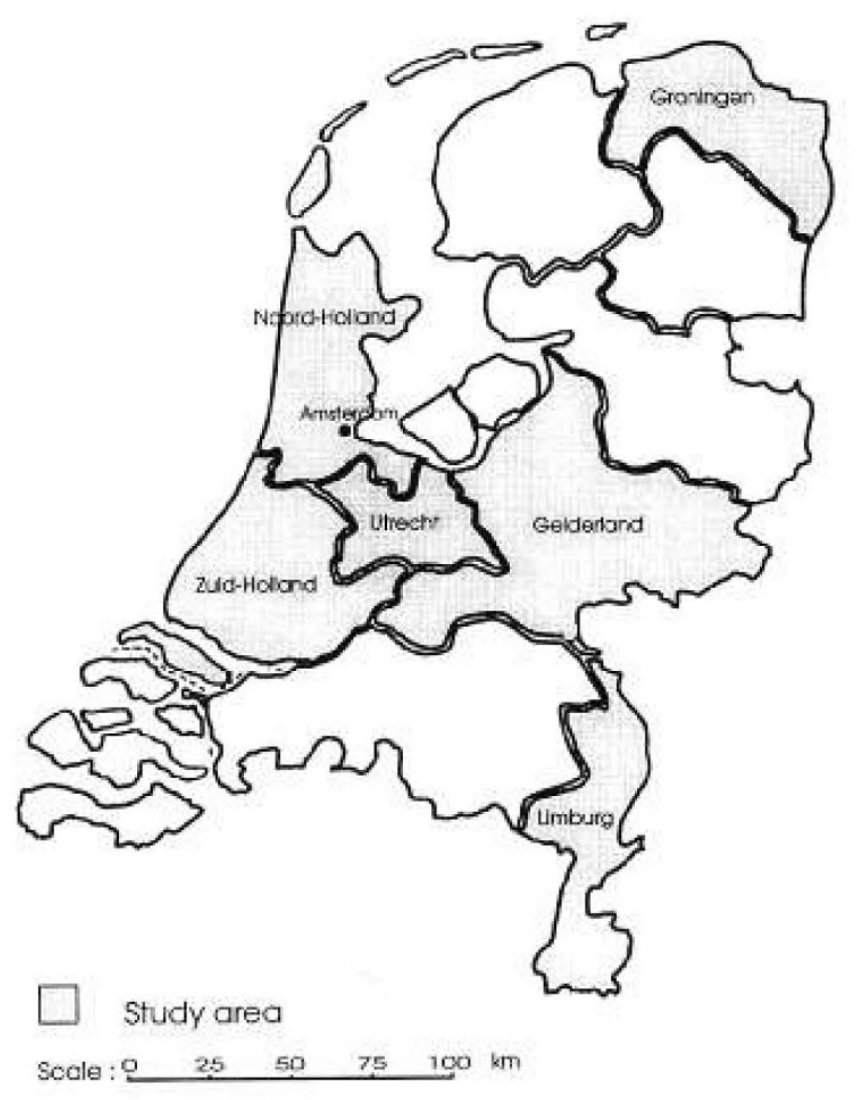

Figure 1. The Netherlands-study area.

eight percent of all children born in The Netherlands regularly visit Community Child Health Care Centres. In these centers, nurses and doctors check health and development and record weight and height on growth charts eight to 12 times during the first $4 \mathrm{y}$ of life. All children attend $12 \mathrm{y}$ of compulsory school free of charge, with at least two medical checkups (13).

Between March 1991 and March 1993, all pediatricians working in the study area were asked by letter if they had any celiac patients under treatment. In the university hospitals, the pediatric gastroenterologists and the head of the outpatient clinic were addressed. The pediatricians who answered in the affirmative and those who did not respond were contacted by telephone.

Minimal inclusion criteria were as follows: 1 ) born in one of the six provinces studied; 2) diagnosis of celiac disease according to the revised ESPGAN criteria (14) based on at least one small-intestinal biopsy, showing (sub)total villous atrophy followed by a clinical or histologic response to a gluten-free diet (These diagnostic criteria are broader than the original ESPGAN criteria (15), which required three small-intestinal biopsies. However, the data do permit the calculation of the incidence rate according to the stricter ESPGAN criteria.); 3) age at diagnosis (first small-intestinal biopsy) before age 15; and 4) celiac disease diagnosed from January 1975 to January 1991.

Additional sources of information were the anonymous membership records of the Dutch Celiac Disease Society, which has existed since 1974, and the data of the Dutch National Medical Registration, which has anonymously regis- tered all diagnoses at discharge from hospital since 1975. If a possible celiac patient was found in a certain hospital through these sources, the pediatrician of the hospital was contacted again.

Informed consent was asked of the parents or patients to allow examination of the medical files, which were consulted for sex, date and place of birth, pattern of breast-feeding, age at gluten introduction, onset of symptoms, symptoms at presentation, age at diagnosis, number of small-intestinal biopsies, associated diseases, adherence to a gluten-free diet, and physical condition based on first and last measured height and weight.

Ascertainment. The data provided by the pediatricians, the Dutch Celiac Disease Society, and the Dutch National Medical Registration were cross-checked with the information of the Dutch Network and National Database of Pathology, which has registered the pathologic specimens taken in The Netherlands since 1975. Thus, if a patient was found via one of the three sources mentioned above, his or her records were checked in the Database of Pathology. However, if a possible celiac patient was found in this Database, but not via one of the three sources, we returned to the pediatrician to ask whether our finding was correct.

The study was approved by the Medical Ethical Committee of the University Hospital Leiden.

Data report and statistical analysis. The crude incidence rate of diagnosed childhood celiac disease was calculated using the number of children aged $0-14$ y developing celiac disease in a given year as the numerator and the number of live births in that same year as the denominator, expressed per 1000. The 0 - to 3-y age-specific cumulative incidence rate was calculated by using as the numerator the number of patients with celiac disease born in a defined year, whose celiac disease was diagnosed from their year of birth to the age of $3 \mathrm{y}$, and as the denominator the number of live births in that same year, expressed per 1000 . Unless indicated otherwise, the prevalence rate of diagnosed childhood celiac disease was calculated using the number of children with celiac disease aged $0-14 \mathrm{y}$, at a certain date, as the numerator and the total number of children age $0-14$ as denominator, expressed per 100000 .

$\chi^{2}$ test for contingency tables, including comparison of figures obtained in different years in The Netherlands and in different European countries, and regression analysis were used; $p<0.05$ was accepted as statistically significant. Where required, results were expressed as mean values $\pm \mathrm{SD}$. Binomial distribution was used to calculate the $95 \%$ confidence intervals for the age-specific cumulative incidence rates.

\section{RESULTS}

Response. Of 195 pediatricians contacted, 191 responded to our inquiry $(97.9 \%)$ and $46.1 \%$ had celiac patients under treatment. A total of 279 celiac patients were identified in this manner. By investigating the membership records of the Celiac Disease Society, we identified 55 additional celiac patients. The survey of the Dutch National Network and Database of Pathology and of the Dutch National Medical Registration provided the data of, respectively, five and three additional 
patients. The information obtained from the pediatricians, the Celiac Disease Society, and the Dutch National Medical Registration corresponded in all cases with the data of the Dutch National Network and Database of Pathology. In total, we identified 342 celiac patients (male:female 1:1.42); $97.3 \%$ of them gave informed consent for further investigation of the medical files. The original ESPGAN criteria for the diagnosis of celiac disease (three small-intestinal biopsies) (15) were met in 152 cases $(44.4 \%)$.

Incidence rate. The mean crude incidence rate of diagnosed celiac disease was 0.18 per 1000 live births, with a minimum of 0.10 in 1976 and a maximum of 0.32 in 1990 (Fig. 2). When only diagnoses according to the original ESPGAN criteria were included, the crude incidence rate over the whole period was 0.08. A significant increase in total incidence from 0.14 in 1975-1979 (16 cases per year) to 0.16 (19 cases per year) in $1980-1984$ to 0.22 in $1985-1990$ (28 cases per year) was found $(p<0.001)$. There were significant differences between the six provinces $(p<0.001)$. The highest total incidence rates in 1975-1990 were found in Limburg and Utrecht (0.25), the lowest in Zuid-Holland and Noord-Holland (0.14). Table 1 shows the crude incidence rates of celiac disease in some European countries (2). There are significant differences between the countries $\left(\chi^{2}=2579.66, d f=7, p<0.001\right)$. The Netherlands and Denmark (16) combined have incidence rates significantly lower than the other countries $\left(\chi^{2}=895.19, d f=\right.$ $1, p<0.001$ ), but regarding each other, no significant differences could be demonstrated. The $0-$ to 3-y age-specific cumulative incidence rates for the period 1975-1987 are shown in Table 2. From 1975-1979 to 1985-1987, an increase in incidence can be observed, which is not significant $(p=0.11)$.

Prevalence rate. The prevalence rate of diagnosed celiac disease per 100000 inhabitants of all ages varied from 1.00 in 1980 to 2.76 in 1990 (Table 3). Using the original ESPGAN criteria, the prevalence rates were 0.51 in 1980 and 1.24 in 1990. The prevalence rate per 100000 children aged $0-14$ y was 4.7 in 1980 and 15.1 in 1990 . For the children diagnosed according to the original ESPGAN criteria, the prevalence rates in the same years were 2.4 and 7.0 , respectively. The lowest prevalence rate was found in Noord-Holland (11.6) and the highest in Utrecht (20.4).

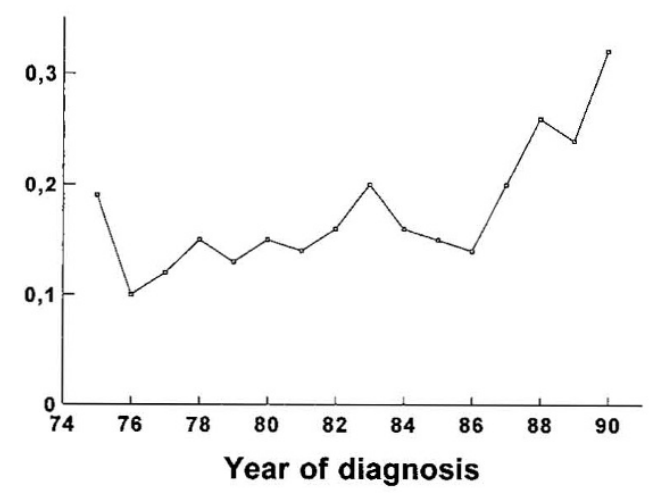

Figure 2. Crude incidence rate of diagnosed childhood celiac disease per 1000 live births in The Netherlands, 1975-1990 (specific data can be obtained from the authors).
Table 1. Crude incidence rates of childhood celiac disease in some European countries (1975-1989)

\begin{tabular}{lc}
\hline \multicolumn{1}{c}{ Countries } & Incidence rate/1000 live births \\
\hline Sweden & 2.42 \\
Italy & 1.00 \\
Spain & 0.70 \\
Germany & 0.45 \\
United Kingdom & 0.44 \\
France & 0.28 \\
The Netherlands & $0.18^{*}$ \\
Denmark & $0.14^{*}$ \\
\hline
\end{tabular}

The incidence rates from the countries other than The Netherlands are taken from the study of Greco et al. (2).

${ }^{*} p<0.001$.

Table 2. Cumulative age-specific incidence rate in children $0-3$ y old of celiac disease (CD) per 1000 live births

\begin{tabular}{cccccc}
\hline & & & & \multicolumn{2}{c}{$95 \%$ confidence } \\
Year of & Live births & CD & Incidence & \multicolumn{2}{c}{ limits } \\
\cline { 5 - 6 } birth & $(n)$ & $(n)$ & rate & Lower & Upper \\
\hline 1975 & 118011 & 10 & 0.08 & 0.04 & 0.16 \\
1976 & 117199 & 12 & 0.10 & 0.05 & 0.18 \\
1977 & 114982 & 15 & 0.13 & 0.07 & 0.22 \\
1978 & 116374 & 13 & 0.11 & 0.06 & 0.19 \\
1979 & 115886 & 13 & 0.11 & 0.06 & 0.19 \\
1980 & 119948 & 15 & 0.12 & 0.07 & 0.21 \\
1981 & 118215 & 14 & 0.12 & 0.06 & 0.20 \\
1982 & 113729 & 11 & 0.10 & 0.05 & 0.17 \\
1983 & 112939 & 10 & 0.09 & 0.04 & 0.16 \\
1984 & 116082 & 11 & 0.09 & 0.05 & 0.16 \\
1985 & 118333 & 14 & 0.12 & 0.06 & 0.20 \\
1986 & 123242 & 18 & 0.15 & 0.09 & 0.23 \\
1987 & 125000 & 21 & 0.17 & 0.10 & 0.26 \\
\hline
\end{tabular}

Table 3. Prevalence rates of childhood celiac disease (CCD) in The Netherlands per 100000 children aged 0-14 y

\begin{tabular}{cccc}
\hline Year & $\begin{array}{c}\text { No. children } \\
0-14 \text { y }\end{array}$ & $\begin{array}{c}\text { CCD } \\
(n)\end{array}$ & $\begin{array}{c}\text { Prevalence } \\
\text { rate }\end{array}$ \\
\hline 1980 & $2,052,843$ & 97 & 4.7 \\
1981 & $2,010,687$ & 112 & 5.6 \\
1982 & $1,963,887$ & 129 & 6.6 \\
1983 & $1,915,850$ & 149 & 7.8 \\
1984 & $1,814,752$ & 164 & 9.0 \\
1985 & $1,825,287$ & 178 & 9.8 \\
1986 & $1,799,189$ & 193 & 10.7 \\
1987 & $1,784,509$ & 210 & 11.8 \\
1988 & $1,779,895$ & 232 & 13.0 \\
1989 & $1,788,088$ & 244 & 13.6 \\
1990 & $1,806,481$ & 272 & 15.1 \\
\hline
\end{tabular}

Clinical picture. The clinical picture at presentation did not change significantly during the study period. The most common symptoms at presentation were abdominal distension (76.0\%), chronic diarrhea (71.3\%), and growth failure $(63.2 \%)$. Figure 3 shows the new cases of celiac disease by age group and year of diagnosis. At the time of diagnosis, $58.8 \%$ of the celiac children were younger than $2 \mathrm{y}$ old, and of these children, $48.2 \%$ were diagnosed according to the original ESPGAN criteria; $12.8 \%$ were older than $7 \mathrm{y}$. The mean age at diagnosis was $3.0 \pm 3.0 \mathrm{y}$. The time between onset of the symptoms and diagnosis was $15.6 \pm 23.6 \mathrm{mo}(0.4-163.4 \mathrm{mo})$.

Of 225 celiac children, $8.9 \%$ had an associated disease such as selective IgA deficiency (5), diabetes mellitus type I (4), 


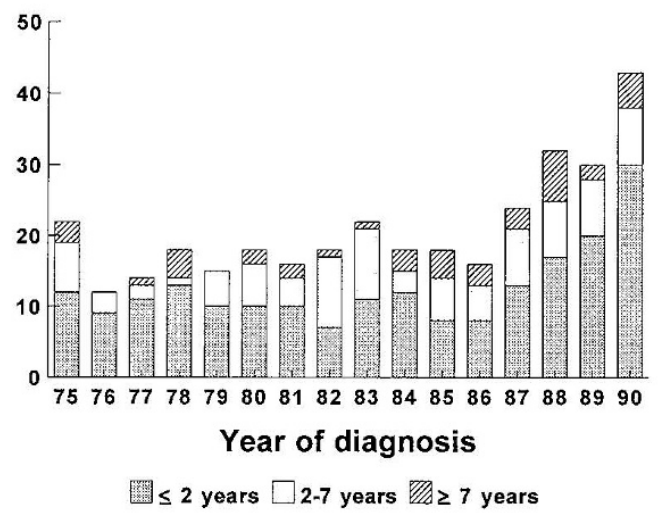

Figure 3. New cases of celiac disease by age group and year of diagnosis.

Down's syndrome (2), cystic fibrosis (2), alopecia (2), cow's milk protein allergy (2), epilepsy (1), juvenile rheumatoid arthritis (1), and chronic autoimmune hepatitis (1). Of the children, 70.2 and $42.2 \%$ were below the 10 th percentile for, respectively, weight and height at the moment of diagnosis. After being on a gluten-free diet for 0.7 to 17.5 y $(6.9 \pm 4.7$ SD), only $9.9 \%$ of the children were below the 10 th percentile for weight and height. Eighty percent (80.3\%) of all celiac patients were members of the Dutch Celiac Disease Society.

Numbers of small intestinal biopsies taken (according to the Dutch National Database of Pathology). In 1985-1990, 2310 small intestinal biopsies were performed on children aged 0-14 y. Of these patients, 238 showed subtotal villous atrophy, which is a sign of celiac disease (ratio 1:10). Figure 4 shows a significant positive correlation between the yearly incidence of diagnosed childhood celiac disease and the number of biopsies per 1000 live births for the period 1985-1990 $(r=0.87, p<$ 0.05 ). To find out whether, in the course of this period, a change in the frequency of subtotal villous atrophy occurred in relation to the total number of small intestinal biopsies, we calculated the yearly ratio and found no significant difference with a mean ratio of 1:9.7 \pm 1.7 for every year.

\section{DISCUSSION}

To investigate whether the incidence and prevalence of celiac disease in The Netherlands were really as low as had been reported (11), we started an extensive survey on the

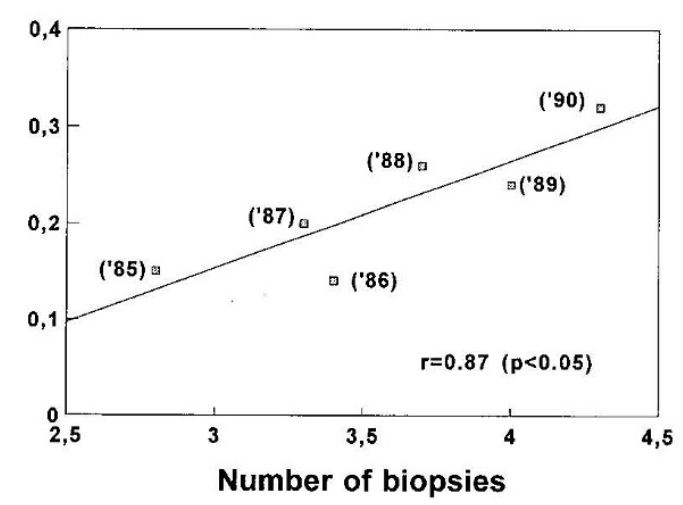

Figure 4. Plotting of the crude incidence rate of diagnosed childhood celiac disease by the number of small-intestinal biopsies taken per 1000 live births, 1985-1990. epidemiology of diagnosed celiac disease in Dutch children in six Dutch provinces ( $70 \%$ of the total population) with a stable emigration/immigration rate. We relied not only on the records of the Celiac Disease Society, but also on all pediatricians working in the area and on the data of the Dutch Medical Registration. The risk of incorrect diagnosis of celiac disease was minimized by including only those children with at least one intestinal biopsy that showed (sub)total villous atrophy, as ascertained by the Dutch Network and National Database of Pathology. Both the high response to our inquiry among the pediatricians (97.7\%) and our final method of ascertainment give reliability to our findings.

In $48.2 \%$ of the children aged younger than $2 \mathrm{y}$ at diagnosis of celiac disease, the strict original ESPGAN criteria were applied. Interestingly, $71.7 \%$ of the children in whom the disease was diagnosed before the age of $2 y$ and in whom the original ESPGAN criteria were not applied received their diagnosis after 1988. This can be explained in part by the short follow-up of this group, which has not yet reached the age necessary to undergo a gluten challenge. Another possibility is that the behavior of the pediatricians concerning the diagnosis of celiac disease has been relaxed during the last few years, partially because of an incorrect interpretation of the revised ESPGAN criteria for diagnosis (14).

The mean crude incidence rate for diagnosed childhood celiac disease in $1975-1990$ is $0.18 / 1000$ live births, which is significantly lower than the incidence rates found in other European countries (Table 1), although it is in line with recent data from Denmark (16). A clear increase in reported incidence is found from $1976(0.10)$ to $1990(0.32)$. The best estimate of the present crude incidence is 0.22 for the period 1985-1990, because during this period more than $90 \%$ of all the pathologic specimens taken in The Netherlands were registered by the Dutch Network and National Database of Pathology, which makes the best possible ascertainment of the incidence. Even this crude incidence rate is low in comparison with that in other European countries. The 0- to 3-y age-specific cumulative incidence rate, chosen because most cases present at an early age, shows the same trend in increase as the crude incidence rate. This can be explained because the number of live births per year remained relatively stable in The Netherlands during the study period. However, the increase in age-specific cumulative incidence rate is not significant, possibly because only the data up to 1988 could be analyzed.

One possible explanation for the low incidence of celiac disease found in The Netherlands is underdiagnosis, caused by an increase in atypical presentation of celiac disease (7). The majority of the celiac patients identified in our study presented themselves at a classic age (younger than $2 \mathrm{y}$ ) with a typical clinical picture of abdominal distension, chronic diarrhea, and growth failure. In Denmark, the only European country with a low incidence rate of identified childhood celiac disease comparable to the one found in The Netherlands (16), an important increase of atypical clinical presentation has been reported. In Sweden, the European country with the highest incidence rate of childhood celiac disease, most of the children, like the Dutch children, present with the typical complaints of chronic diarrhea and malabsorption. However, whereas in Denmark the 
incidence of celiac disease has remained stable, the incidence rate in The Netherlands has increased significantly since 1975. Therefore, it seems reasonable to assume that the increase in incidence of celiac disease in The Netherlands largely depends on the increase of "classic" celiac disease. If this is the case, it does not seem likely that a changing clinical picture accounts for the low incidence of childhood celiac disease. However, the possibility that atypical forms of the disease are underdiagnosed in our country still remains. We are currently investigating this subject.

Another possible explanation for the low incidence found could be a low frequency in the Dutch population of the genetic factors associated with celiac disease: HLA-DR3-DQ2 (17). However, the frequencies of the associated HLA genes in The Netherlands (HLA-DR3: 0.13; HLA-DQ2:0.21; G. M. T. Schreuder, personal communication) are similar to or higher than those found in countries with a high incidence of celiac disease, such as Sweden (HLA-DR3: 0.15; HLA-DQ2: 0.13) (18).

Environmental factors such as feeding practices could be the cause of the variations in incidence of celiac disease in different countries. For example, the high gluten content in the diet of 9-mo-old Swedish children (3573 $\mathrm{mg}$ of gluten per day) compared with the low gluten consumption by the Danish children at the same age (667 $\mathrm{mg}$ of gluten per day) has been implicated in the great difference in incidence and symptomatology between the two countries (6). The late and gradual introduction of gluten in the diet in The Netherlands, as recommended by the Community Child Health Care Centres since 1985 (19), is very similar to the policy followed by the Danish National Bond of Health. However, the gluten consumption of the average Dutch child at the age of $9 \mathrm{mo}$ is about $2000 \mathrm{mg}$ of gluten per day (20). This high gluten intake is largely due to the fact that the cereal consumption by the Dutch children at this age $(43.6 \mathrm{~g} / \mathrm{d})$ mainly consists of wheat $(69.9$ $\mathrm{mg}$ of gluten per gram), whereas in Denmark the main type of cereal consumed $(35.5 \mathrm{~g} / \mathrm{d})$ is rye ( $5.8 \mathrm{mg}$ of gluten per gram) (21). However, the incidence of childhood celiac disease in Finland (1975-1989) is four times as high as in The Netherlands (2), but the amount of gluten intake at the age of 9 mo is half the amount that Dutch children ingest (6). Thus, the extent to which the quantity of gluten intake really influences the incidence of celiac disease remains questionable. Breastfeeding is considered to be protective against celiac disease at the youngest age and might postpone signs and symptoms (22). In The Netherlands, the percentage of children who are being breast-fed at the age of 3 mo has increased significantly since $1975(p<0.05)(13)$. Among the celiac children, the same change in the pattern of breast-feeding has taken place (Table 4). Nevertheless, it is in the youngest age group that the increase in diagnosis of celiac disease during the last years is most marked.

Table 4. Percentages of Dutch celiac children (CCD) and Dutch children (DC) receiving breast-feeding on 190

\begin{tabular}{lccc}
\hline & $1975-1979$ & $1980-1984$ & $1985-1990$ \\
\hline CCD & 9.1 & $25.0^{*}$ & $33.6^{*}$ \\
DC & 10.9 & $27.1^{*}$ & $31.9^{*}$ \\
\hline
\end{tabular}

${ }^{*} p<0.05$ (with regard to previous period).
In The Netherlands, we have found a significant positive correlation between the yearly incidence of diagnosed childhood celiac disease and the number of small-intestinal biopsies taken. However, the ratio of biopsies with subtotal villous atrophy to the total number of biopsies remains stable (1:10 per year). To investigate whether a real increase in the incidence of celiac disease is occurring in The Netherlands, it is necessary to systematically screen (and take biopsies from) large parts of the population. However, our data suggest first that the more small-intestinal biopsies taken, the more celiac patients diagnosed, and second that the increase in diagnosed celiac disease does not result from a parallel increase of small-intestinal alterations, but from a higher awareness among pediatricians.

Celiac disease is a potentially premalignant disorder in adults (23) and children (24). A life-long gluten-free diet seems to protect the celiac patient against the development of a malignancy (23) and should be advised in all cases. Whether the recent increase in diagnosis of celiac disease in The Netherlands is the result of a real increase in incidence or not, it results in more Dutch people who are at risk for this serious complication and who should consume a gluten-free diet.

In conclusion, even our highest estimate of the crude incidence rate of childhood celiac disease in The Netherlands, $0.22 / 1000$ live births in 1985-1990, remains below the rates reported by all other European countries, excluding Denmark. Underdiagnosis, the amount of gluten intake at a young age, and breast-feeding do not seem to explain the low incidence in The Netherlands. A significant positive correlation was found between the number of small-intestinal biopsies taken and the number of identified cases of childhood celiac disease. A clear increase in incidence of childhood celiac disease from 1976 to 1990 was found, but it is uncertain whether the incidence will continue to increase.

Acknowledgments. The authors thank B. T. C. Flapper from the Juliana Children's Hospital, The Hague, H. C. M. Franken from the department of Medical Statistics, University Hospital Leiden, Ph. J. Hoedemaeker and I. J. A. M. G. Casparie-van Velsen from the Dutch Network and National Database of Pathology, and R. R. M. de Groot from the Dutch National Medical Registration and the Dutch Celiac Disease Society for their collaboration; S. P. Verloove-Vanhorick and L. J. Dooren for critical reading; and Nutricia Nederland for financial support.

\section{REFERENCES}

1. Mylotte M, Egan-Mitchell B, McCarthy CF, McNicholl B 1973 Incidence of coeliac disease in the West of Ireland. BMJ 1:701-756

2. Greco L, Mäki M, Di Donato F, Visakorpi JK 1992 Epidemiology of coeliac disease in Europe and the Mediterranean Area. In: Auricchio S, Visakorpi JK (eds) Common Food Intolerances I: Epidemiology of Coeliac Disease. Karger, Basel, Switzerland, pp $24-44$

3. Berg NO, Lindbergh T 1979 Incidence of coeliac disease and transient gluten intolerance in children in a Swedish urban community. Acta Paediatr Scand 68:397-400

4. Ascher H, Krantz I, Kristiansson B 1991 Increasing incidence of coeliac disease in Sweden. Arch Dis Child 66:608-611

5. Challacombe DN, Baylis JM 1980 Childhood coeliac disease is disappearing. Lancet 2:1360

6. Michaelsen KF, Weile B, Larsen P, Samuelson G, Krasilnikoff PA 1993 Does the low intake of wheat in Danish infants cause the low incidence rate of coeliac disease? Acta Paediatr 82:605-606

7. Mäki M, Kallonen K, Lahdeaeho ML, Visakorpi JK 1988 Changing pattern of coeliac disease in Finland. Acta Paediatr Scand 77:408-412

8. Anonymous 1983 Infertility in coeliac disease. Lancet 1:453-454 
9. Depla ACIM, Bartelsman JFWM, Mulder CJJ, Tytgat GNJ 1990 Anemia: monosymptomatic coeliac disease. Hepatogastroenterology 37:90-91

10. Swinson CM, Levi AJ 1980 Is coeliac disease underdiagnosed? BMJ 281:1258-1260

11. Jansen TLThA, Mulder CJJ, Karssen PHZ, Wagenaar CGJ 1993 Epidemiological survey of the Dutch Coeliac Disease Society: an update 1992. Eur J Gastroenterol Hep 5:73-78

12. Population of the Municipalities of The Netherlands at January 1st 1991. SDU/ Publishers Netherlands Central Bureau of Statistics, The Hague

13. Annual Report of the Dutch Child Health Care Inspection 0-4 Years, 1975-1990

14. Walker-Smith JA, Guandalini S, Schmitz J, Shmerling DH, Visakorpi JK 1990 Revised criteria for diagnosis of coeliac disease. Report of Working Group of ESPGAN. Arch Dis Child 65:909-911

15. Meeuwisse GW 1970 Diagnosis criteria in coeliac disease. Acta Paediatr Scand 59:361-363

16. Weile B, Krasilnikoff PA 1992 Low incidence rates by birth of symptomatic coeliac disease in a Danish population of children. Acta Paediatr 81:394-398

17. Sollid LM, Thorsby E 1990 The primary association of celiac disease to a given HLA-DQ alpha/beta heterodimer explains the divergent HLA-DR associations observed in the various Caucasian populations. Tissue Antigens 36:136-137
18. Bauer MP, Neugebauer M, Deppe H, Sigmund M, Luton T, Mayer WR, Albert ED 1984 Population analysis on the basis of deduced haplotypes from random families. In: Albert ED, Bauer MP, Mayer WR (eds) Histocompatibility Testing 1984. Springer-Verlag, New York, pp 333-341

19. Van der Avert FJ, de Bekker GJPM, van Beurden MG, Douwes AC, Fernandes J, Hammink J, Knopf XEAM, van Kuppevelt AJM, Lim M, van Meer WA, Phaff JNL, Uitentuis J, Voorhoeve HWA, Visser HKA, Studygroup on infant feeding 1985 Zuigelingen-voeding, de huidige inzichten. Tijdschr Kindergeneeskd 53(suppl):1-48

20. Horst CH, Obermann-de Boer GL, Kromhout D 1987 De voeding van vier, zes en negen maanden oude Leidse zuigelingen. Voeding 48:173-176

21. Friis SU 1988 Enzyme-linked immunosorbent assay for quantitation of cereal proteins toxic in coeliac disease. Clin Chim Acta 178:261-270

22. Challacombe DN 1983 The incidence of coeliac disease and early weaning. Arch Dis Child 58:326

23. Holmes GKT, Prior P, Lane MR, Pope D, Allan RN 1989 Malignancy in coeliac disease. Effect of a gluten-free diet. Gut 30:336-339

24. Stahlberg MY, Savilathi E, Teppo L 1992 Coeliac disease from childhood-increased risk for malignancy. J Pediatr Gastroenterol Nutr 15:346(abstr 36) 